\title{
Fiber Optic Sensing for Monitoring Corrosion-Induced Damage
}

\author{
M. Maalej", \\ Assistant professor, Department of Civil Engineering, National University of Singapore, \\ 1 Engineering Drive 2, Singapore 117576. Tel. (65)-6874-4913, Fax. (65)-6779-1635, \\ E-mail: cvemm@nus.edu.sg \\ S.F.U. Ahmed \\ Research scholar, Department of Civil Engineering, National University of Singapore, \\ 1 Engineering Drive 2, Singapore 117576. \\ E-mail: engp9621@nus.edu.sg \\ and \\ P. Paramasivam \\ Professor, Department of Civil Engineering, National University of Singapore, \\ 1 Engineering Drive 2, Singapore 117576. \\ E-mail: cveparam@nus.edu.sg
}

*Corresponding author 


\begin{abstract}
This paper studies the feasibility of using fiber optic sensing technology to monitor corrosion-induced damage in reinforced concrete $(\mathrm{RC})$ beams. Five series of $\mathrm{RC}$ beams were subjected to varying degrees of corrosion-induced damage by varying the composition of the concrete mix and subjecting all specimens to the same accelerated corrosion environment. A concrete-embeddable fiber optic strain sensor (FOSS) was used in each corroded beam to measure the corrosion-induced tensile strains in the concrete and the tendency of the concrete cover to delaminate. A correlation between the FOSS strain and the amount of steel loss due to accelerated corrosion was established. Correlations have also been established between the FOSS strains and the reduction in the load carrying and the midspan deflection capacity at failure. The proposed technique was found to be useful in detecting corrosion-induced damage in RC structures where visual inspection is not possible.
\end{abstract}

Key words: Fiber optic strain sensor; corrosion damage; spalling; delamination; correlation; structural health monitoring. 


\section{INTRODUCTION}

A structure with a structurally-integrated fiber optic sensing system has been referred to in literature as a smart structure [1-5]. In recent years, the use of fiber optic sensors in civil engineering applications has been the focus of considerable research. Because of their small size and lightweight, fiber optic sensors can be easily integrated into new or existing structures, thereby, offering new and improved techniques for structural health monitoring of instrumented structures.

The deterioration of reinforced concrete structures due to reinforcement corrosion has been recognized as a major problem worldwide [6]. The corrosion of a reinforcing bar is accompanied by the production of iron oxides and hydroxides, which occupy a volume larger than the original metal. As a result, a large pressure is exerted on the surrounding concrete, which results in local radial cracks. These cracks can propagate along the bar, producing longitudinal cracks, which can lead to severe corrosion problems [7]. This is because the corrosion reaction can develop and continue along the bar resulting in general corrosion. Consequently, a significant bursting pressure is created by the corrosion products resulting in further cracking and in extreme cases spalling of the concrete, especially at corner bars [8]. When spalling of the concrete cover occurs, the corrosion process accelerates (corrosion of exposed bars may occur at about 10 times the rate at which it occurs at a crack [9]), and the member is likely to experience loss of strength. In addition, a large crack may form parallel to the concrete surface at a plane of bars, resulting in the delamination of the surface, a serious problem in bridge decks [7].

Key to the successful upgrading and maintenance of aging infrastructure facilities is timely detection and quantification of damage, particularly so for damage which builds-up over time during the functional life of the structure, such as corrosion-induced damage. In this study, a fiber optic sensing technique is proposed for the long-term monitoring of 
corrosion-induced damaged in $\mathrm{RC}$ beams. Five series of $\mathrm{RC}$ beams were subjected to varying degrees of corrosion-induced damage by varying the composition of the concrete mix and subjecting all specimens to the same accelerated corrosion environment. With the use of a concrete embeddable fiber optic strain sensor (FOSS), the tendency of the concrete cover to delaminate due to reinforcement corrosion was measured. The use of fiber optic sensing technology in this manner provides an additional means of monitoring corrosion-induced damage in RC structures where visual inspection is not possible.

\section{REPORTED APPLICATIONS OF FIBRE OPTIC SENSING TECHNOLOGY}

Fibre optic sensors applied to structural engineering components and systems have been reported extensively. Fuhr et al. [10] reported the use of fiber optic sensors in reinforced concrete beams. Their study involved the embedding of optical fibers of various types inside small RC beams. The initial tests focused on whether the optical fibers could survive during concrete embedding and curing process. Three out of four fibers survived. The beams were also loaded in four-point bending until failure. Maher and Nawy [11] reported the successful use of fiber optic bragg grating strain gauges in laboratory concrete beam tests. Ansari [12] reported the development of a fiber optic probe that is capable of measuring the amount of air entrained in fresh concrete. Microbend technology, where the fiber is spirally wrapped around the reinforcing steel, has been used to measure the dynamic propagation of cracks in concrete beams under bending [13]. Measures et al. [14] reported the use of fiber optic sensing technique to monitor the changes in the internal strain of prestressing tendons and deck girders of highway bridge arising from both static and dynamic

loadings. In a separate study, Prohaska et al. [15] measured the strain in steel rebars of RC beams using fiber optic bragg grating strain sensors which were bonded to the rebar. The use of fiber bragg grating strain sensor in reinforced concrete beams and slabs is also reported by 
Davis et al. [16]. In their study, the strain levels in concrete structures were measured up to failure of the specimens. Fibre optic sensors have also been used to monitor the structural response in different types of existing structures, such as power plant boiler, light poles, bridges etc. [17-21].

\section{EXPERIMENTAL PROGRAM}

Five series of reinforced concrete beams were cast in this investigation. Each series consisted of two identical beams. The composition of the concrete mix for the first four series was varied by introducing supplementary cementing materials (SCM) such as fly ash (FA), slag (SG), and silica fume (SF) used as partial replacement of ordinary Portland cement (OPC) in the concrete. In the fifth series, the OPC concrete that surrounds the tensile reinforcement was replaced with a ductile fibre reinforced cementitious composite (DFRCC) containing 1.5\% PVA (Polyvinyl alcohol) and 1.0\% steel fibers resulting in the concept of Functionally-Graded Concrete (FGC) shown in Figure 1 [22]. This is done to create varying tendencies for the concrete cover to delaminate due to reinforcement corrosion.

Beams cast using OPC, FA, SG, SF and FGC concrete were designated as series 1,2,3, 4 and 5, respectively as shown in Table 1 . In each series, one specimen was subjected to accelerated corrosion while the second was kept as control in order to compare its loaddeflection behavior with the corroded specimen. Corrosion-induced damage in the concrete beams was evaluated by measuring the corrosion current throughout the accelerated corrosion test. In addition, the size and location of cracks were monitored visually and sketched on the paper as they appeared. A fiber optic strain sensor was used in each corroded beam to measure the corrosion-induced tensile strains of the concrete at the level of tensile steel reinforcement and the tendency of the concrete cover to delaminate. A detailed test plan is given in Table 1. 


\section{Materials}

The concrete mix proportions used in this experimental program are given in Table 2. Mix 1 is the control concrete with $100 \%$ ordinary Portland cement and a water-to-binder (W/B) ratio of 0.42. This mix satisfies the ACI requirements for corrosion protection of reinforcement in concrete exposed to chlorides. In Mix 2 and Mix 3, 50\% of the cement was replaced by fly ash and slag, respectively. In Mix 4, $10 \%$ of the cement was replaced by silica fume.

For the fifth series of specimens (the FGC specimens), two different mixes were used. The first mix was an ordinary Portland cement concrete used in the top two-third portion of the beams and is designated as Mix 5A. The other was a ductile fibre reinforced cementitious composite (DFRCC) mix used in the lower one-third portion of the beams and is designated as Mix 5B. Details on the mix proportions of the DFRCC material and the plain concrete used in the fifth series are also given in Table 2.

\section{Specimen Fabrication}

All RC beams were $2.5 \mathrm{~m}$ in length and had identical cross sections measuring $300 \mathrm{x}$ $210 \mathrm{~mm}$ (Figure 2). The longitudinal reinforcements consisted of $3-16 \mathrm{~mm}$ diameter deformed bars in the tension zone and $2-13 \mathrm{~mm}$ diameter deformed bars in the compression zone, corresponding to reinforcement ratios of $1 \%$ tensile and $0.4 \%$ compressive. Shear reinforcement consisted of $6 \mathrm{~mm}$ plane bar stirrups spaced at $80 \mathrm{~mm} \mathrm{c} / \mathrm{c}$ in the shear span and $120 \mathrm{~mm} \mathrm{c/c}$ in the constant moment region.

Concrete embeddable fiber optic strain sensors (FOSS) were installed in beams B1C, B2C, B3C, B4C and B5C, which were subjected to accelerated corrosion. In each beam, one FOSS was placed vertically between two longitudinal bars at the mid-span as shown in Figure 2. Sufficient care was taken during casting in order to avoid any possible damage to the FOSS during vibration. After casting, all specimens were wet cured for 28 days. 


\section{Accelerated Corrosion and Monitoring System}

Five beams (B1C, B2C, B3C, B4C and B5C) were subjected to an electrochemical accelerated corrosion environment achieved by subjecting the specimens to cyclic wetting and drying (3.5 days wetting and 3.5 days drying) using water containing 3\% (by weight) sodium chloride and impressing a current using a fixed electrical potential applied across an internal anode (the steel reinforcement) and an external cathode built from a 3mm-diameter wire mesh with $15 \mathrm{~mm}$ square openings. The applied potential and resulting current values were automatically recorded using a data acquisition system and a personal computer. The measured current was used to calculate an estimated corrosion-induced steel loss using Faraday's law [23]:

$$
\Delta w=\frac{M I t}{Z F}
$$

where $\Delta w$ is the mass of steel loss (grams), $\mathrm{I}$ is the corrosion current (amperes), $\mathrm{t}$ is time (seconds), F is the Faraday's constant (96,500 amperes seconds), $\mathrm{Z}$ is the valency of Fe (2), and $\mathrm{M}$ is its atomic mass (56 grams/mole).

\section{Monitoring Corrosion Damage Using Fiber Optic Sensing Technique}

In this study, a concrete-embeddable fiber optic strain sensor (Fabry-Perot type) was used to monitor the corrosion-induced tensile strain in the concrete at the level of longitudinal tension reinforcement where splitting cracks were likely to occur (see Figures 3 and 4). The Fabry-Perot strain gauge itself is bonded in a very small diameter longitudinal hole located in the center of a concrete embeddable stainless steel body measuring $70 \mathrm{~mm}$ in length and having two flanges at both ends for better adherence to concrete. The advantage of this fiber optic strain sensor over its conventional counterparts is that it provides stable absolute measurement of strain needed in experiments involving long-term monitoring [24]. Fiber 
optic cables connect the sensors to an eight-channel portable reading unit (called Bus system). Data from all channels are read simultaneously throughout the accelerated corrosion period and stored by a data acquisition software in a personal computer.

\section{RESULTS AND DISCUSSIONS}

\section{Corrosion Currents and Steel Loss}

The FGC beam and all SCM-modified concrete beams showed better corrosion resistance, in terms of lower corrosion current and visual damage, than the OPC concrete beam. Figure 5 shows the average corrosion current for all five beams that were subjected to accelerated corrosion. From this Figure it can be seen that the OPC concrete beam attained the highest measured current among all beams. The FA concrete beam attained the lowest measured current indicating the highest corrosion resistance. During the wet phase, the measured current was higher than during the dry phase because the ionic conductivity of wet concrete is higher than that of dry concrete. As expected, the amount of steel loss in the OPC concrete beam was the highest among all beams. This beam lost $9.7 \%$ of its internal steel reinforcement. At the same age, the FA, SG, SF and FGC concrete beams lost about 3.3, 4.6, 7.0 and $6.6 \%$ of their internal steel reinforcement, respectively (see Table 3).

\section{FOSS Readings}

Figure 6 shows the variation of concrete strain as measured by the FOSS over time. During the first 32 days, there was no significant change of strain in all four beams except the FGC beam. After the first 32 days, the strain in the OPC concrete beam started to increase; this was associated with the development of a longitudinal crack at the level of tension steel reinforcement. The strain in the same specimen continued to increase with the progress of corrosion. A single longitudinal crack in the SF concrete beam also formed after about 37 days. In addition, it could be verified from Figure 6 that the FOSS strain in this beam also 
increased at that time. This indicates that fiber optic sensing could indeed be used to detect cracking in concrete due to corrosion of steel reinforcement.

As soon as a corrosion-induced crack forms, the crack width starts to increase allowing corrosion products to be released into the exterior. As a result, the exerted pressure due to the expansion of the steel starts to reduce. This situation is believed to have taken place in both the OPC and the SF concrete beams, where after about 42 days the rate of increase in the FOSS strains started to reduce.

In the case of SG and FA concrete beams, the highest FOSS strains measured were only about 288 and 185 micro-strains, respectively. Moreover, no sudden increase in strain similar to that observed in the OPC and SF concrete beams occurred in both beams (see Figure 6). This was because of the low level of steel loss in those beams compared to the OPC and SF concrete beams.

While all SCM-modified concrete beams were subjected to accelerated corrosion uncracked, load-induced cracks were introduced in the FGC beam prior to subjecting it to accelerated corrosion. This resulted in an earlier initiation of corrosion and an initially higher corrosion current in the former beam compared to the latter ones. As result, the FOSS in the FGC beam recorded a noticeable increase in the strain after only one week of accelerated corrosion. Table 3 indicates that the FOSS reading in the FGC beam was only 277 microstrains as a result of $6.6 \%$ steel loss. It is interesting to note that the FOSS reading in the FGC beam is very close to that recorded in the SG concrete beam (288 micro-strains), although the steel loss in the latter is about $4.6 \%$, which is about $30 \%$ lower than that in the FGC specimen. Visual inspections of the FGC beam and results shown in Figure 6 for the same beam indicated the absence of any corrosion-induced cracking or any sudden increase in the FOSS strain reading due to cracking. This can be attributed to the higher tensile strain capacity and fracture resistance of the DFRCC material compared to the OPC, SF, SG and 
FA concrete materials. The fibers in the DFRCC material suppress the growth of the cracks and prevent strain localization, resulting in higher damage tolerance.

Further evidence on the above can be seen in Figure 7, which shows the increase in the FOSS strain reading with the cumulative steel loss due to accelerated corrosion. In Figure 8, the highest FOSS strain reading is plotted against the total amount of steel loss recorded in each specimen. The figure indicates a general trend of increasing FOSS strain with increasing steel loss. A clear deviation from this general trend of behavior can be seen for the FGC specimen. Again, the figure indicates that smaller corrosion-induced tensile strain develops in the FGC specimen compared to other specimens for similar amounts of steel loss.

\section{Crack Mapping}

Throughout the accelerated corrosion process, the size and location of cracks were sketched on paper as they appeared (Figure 9). In all cases, except the FGC beam, longitudinal cracks on both sides of the beam along the tension reinforcement formed followed by some branch cracks. Cracks along stirrups were also noticed in the bottom half of the beams. In the OPC concrete beam, more cracks were observed than in any of the other beams. This is probably the result of larger steel loss that occurred in this beam compared to the others. In the SF concrete beam, the number of corrosion-induced cracks was more than those observed in the FA and SG concrete beams, where longitudinal cracks formed after about 65 and 60 days, respectively (compared to 32 and 37 days in the case of the OPC and SF concrete beams, respectively).

In the case of the FGC beam, no corrosion-induced cracks were observed even after $6.6 \%$ steel loss. Instead, leaching of soft corrosion products from few points along the interface between the concrete and the DFRCC material was noticed (Figure 9 (e)). These were believed to be associated with limited corrosion of the stirrups at these locations. 


\section{Structural Testing of Beams}

All corroded and uncorroded beams were tested under four-point loading at a loading rate of $0.015 \mathrm{~mm} / \mathrm{sec}$ using an MTS universal testing machine with a maximum capacity of $500 \mathrm{kN}$. A total of 3 LVDTs were used to measure the midspan and the load-line deflections of the beams during testing.

The load and the deflection capacity at failure for all corroded and uncorroded RC beams are summarized in Table 3. As the table shows, the corroded OPC concrete beam lost about $13 \%$ of its load-carrying capacity and $26 \%$ of its deflection capacity at failure. In the corroded specimen, upon reaching the yield load a longitudinal crack, which had originally formed during the accelerated corrosion test, continued to increase in width as the load continued to increase. That led to slight delamination of the concrete cover upon reaching the peak load (see Figure 10). After structural testing, part of the concrete cover in the corroded OPC concrete beam was removed to expose the reinforcing bars and the stirrups and examine the extent and the uniformity of the steel loss (Figure 10(c)). The examination revealed a fairly uniform loss of steel along the longitudinal and the transverse reinforcement. Few spots of pitting corrosion have also been observed on both the longitudinal and the transverse reinforcement.

In the case of the SF concrete beam, the corroded specimen lost about $9 \%$ of its loadcarrying capacity and $8 \%$ of its deflection capacity at failure. In the corroded SF concrete beam, a corrosion-induced crack also started to open upon reaching the yield load. However, the crack width remained small and no delamination of the concrete cover was noticed in this case.

In the case of the SG concrete beam, the corroded specimen lost $5 \%$ of its load carrying capacity and $21 \%$ of its deflection capacity at failure. On the other hand, the 
corroded FA concrete beam lost only $3 \%$ of its load carrying capacity and $11 \%$ of its deflection capacity at failure. By looking at the cracking patterns during structural testing in both the corroded and uncorroded FA and SG concrete beams, no delamination triggered by corrosion-induced cracks had been noticed. Moreover, the cracking patterns after structural testing in both the corroded and uncorroded beams were almost similar. This is reasonable as the extent of corrosion damage in both beams was very limited.

Finally, in the case of the FGC concrete beam, the corroded specimen lost about 5\% of its load carrying capacity at failure, however, there was no observable reduction in its deflection capacity at failure. Figure 11 shows the cracking patterns that developed in the beam at ultimate load. After testing and with significant difficulty, part of the concrete cover was removed to expose the reinforcing steel for examination. The examination revealed a minimum loss of steel in the longitudinal reinforcement, except for the midpan region where the load-induced precracks were largest in width. In this region, moderate loss of steel could be observed, but there was no evidence for the presence of corrosion-induced radial cracks or delamination around the longitudinal reinforcing bars. As for the stirrups, there was evidence of some pitting corrosion at the interface between the concrete and the DFRCC material, and these must have been the source of the corrosion spots observed at these locations.

Using data from all five series of specimens, correlations between the FOSS readings and the reductions in the load carrying capacity and the deflection capacity at failure have been established as shown in Figure 12. The Figure indicates a general trend of increasing reductions in the load carrying capacity and the deflection capacity at failure with increasing FOSS strains. Deviations from this general trend of behavior can be seen for the FGC beam. Figure 12 indicates that the FGC beam retained its original deflection capacity despite undergoing accelerated corrosion. This can be explained by the fact that the FGC specimen did not suffer any type of cracking or delamination that would have reduced its deflection 
capacity. The reduction in the load carrying capacity at failure is however consistent with the observed general trend and this is reasonable as this reduction is a function of the area of steel lost due to accelerated corrosion. The pitting corrosion that had developed in the stirrups at the interface between the concrete and the DFRCC material did not seem to affect the load-deflection behavior of the beam given the fact that the RC beams were not shear critical.

\section{CONCLUSIONS}

The feasibility of using fiber optic sensing technology for monitoring corrosioninduced damage in RC beams was experimentally studied. A concrete-embeddable fiber optic strain sensor was used to monitor the corrosion-induced tensile strain in the concrete at the level of longitudinal tension reinforcement where splitting cracks were likely to occur. In this case, the tendency of the concrete cover to delaminate due to reinforcement corrosion can be measured. A correlation between the FOSS strain and the amount of steel loss due to accelerated corrosion was established. Correlations have also been established between the FOSS strains and the reductions in the load carrying capacity and the deflection capacity at failure. The use of fiber optic sensing technology in this manner provides an additional means of monitoring corrosion-induced damage in $\mathrm{RC}$ structures where visual inspection is not possible.

\section{ACKNOWLEDGEMENTS}

The authors would like to acknowledge Saanyang Cement Co. Ltd. and National Cement Co. Ltd. of Singapore and for supplying slag and fly ash used in this study. Grateful acknowledgement is also due to Kuraray Co. Ltd. of Japan and Bekaert Co. Ltd. of Belgium for supplying PVA and steel fibers, respectively. Part of this research was supported by a research grant (R-264-000-105-112) from the National University of Singapore. 


\section{REFERENCES}

1. Udd, E. (1995). Fiber Optic Smart Structures, 647-665, John Wiley and Sons, Inc.,New York.

2. Melle S. M. et al. (1993). Practical Fiber-Optic Bragg Grating Strain Gauge System, Applied Optic, 32: 3601-3609.

3. Measures R. M. et al. (1995). A Structurally Integrated Bragg Grating Laser Sensing System for a Carbon Fiber Prestressed Concrete Highway Bridge, Smart Materials and Structures, 4: 20-30.

4. Measures R. M. (1993). Fiber Optic Sensing for Smart Composite Structures, Composite Engineering, 3: 715-750.

5. Measures R. M. (1989). Smart Structures With Nerves of Glass, Prog. Aerosp. Sci., 26: 289-351.

6. Bonacci J. F. and Maalej M. (2000). Externally-Bonded FRP for Service-Life Extension of RC Infrastructure, ASCE Journal of Infrastructure Systems, 6: 41-51.

7. Gergely, P. (1981). Role of Cover and Bar Spacing in Reinforced Concrete, Significant Developments in Engineering Practice and Research, SP-72, American Concrete Institute, Detroit, pp. 133-147.

8. ACI Committee 224. (1991). Control of Cracking in Concrete Structures, ACI Manual of Concrete Practice Part-3-1991: Use of Concrete in Building Design, Specifications and Related Topics, American Concrete Institute, Detroit.

9. Beeby, A. W. (1978). Corrosion of Reinforcing Steel in Concrete and its Relation to Cracking, The Structural Engineer, 56A (3): 77-81.

10. Fuhr, P.L., Huston, D.R. and Ambrose, T.P. (1993). Curing and Stress Monitoring of Concrete Beams Using Embedded Optical Fiber Sensors, ASCE Journal of Structural Engineering, 119 (7): 2263-2269. 
11. Maher, M.H. and Nawy, E.G. (1993). Evaluation of Fiber Optic Bragg Grating Strain Sensor in High Strength Concrete Beams, In Application of fiber optic sensors in engineering mechanics (F. Ansari, ed.), pp. 120-133.

12. Ansari, F. (1991). Rapid In-place Air Content Determination in Fresh Concrete, Concrete International, 13 (1): 39-43.

13. Anasri, F. and Navlurkar, R.K. (1993). A Fiber Optic Sensor for the Ddetermination of Dynamic Fracture Parameters in Fiber Reinforced Concrete, In Application of fiber optic sensors in engineering mechanics (F. Ansari, ed.), pp. 160-176.

14. Measures et al. (1994). Bragg Grating Structural Sensing System for Bridge Monitoring, In the proceedings of the distributed and multiplexed fiber optic sensors, SIPE- the international society for optical engineering, July 27-28, San Diego, USA, 2294 : 53-59.

15. Prohaska et al. (1992). Fiber Optic Bragg Grating Strain Sensor in Large Scale Concrete Structures, In the proceedings of the fiber optic smart structures and skins V, SIPE- the international society for optical engineering, september 8-9, Massachusetts, USA, 1798: 286-294.

16. Davis, M.A., Bellemer, D.G. and Kersay, A.D. (1997). Distributed Fibre Bragg Grating Strain Sensing in RC Structural Components, Cement and Concrete Composites, Vol. 19: 45-57.

17. Inaudi et al. (1999). SOFO: Structural Monitoring with Fiber Optic Sensors, fib commission meeting on monitoring and safety evaluation of existing concrete structures, Vienna, February 12-13.

18. Measures, R.M. (1997). Structural Monitoring with Fiber Optic Bragg Gratings, Intelligent civil engineering materials and structures, ASCE special publications, pp. 180-201. 
19. Abdunur, C. (1997). Direct Measurement and Monitoring of Stresses in Concrete Bridge, Intelligent civil engineering materials and structures, ASCE special publications, 1997, pp. 202-212.

20. Wanser, K.H. and Voss, K.F. (1997). Fiber Optic Strain Monitoring Inside a Power Plant Boiler, Intelligent civil engineering materials and structures, ASCE special publications, pp. 213-228.

21. Abdunur, C. (1997). Monitoring the Influence of Transverse Cracks in Bridges, Intelligent civil engineering materials and structures, ASCE special publications, pp. 243-258.

22. Maalej, M. and Li, V. C. (1995). Introduction of Strain Hardening Engineered Cementitious Composites in Design of Reinforced Concrete Flexural Members for Improved Durability, ACI Structural Journal, 92 (2): 167-176.

23. Lee, C. (1998). Accelerated Corrosion and Repair of RC Columns Using CFRP Sheets, M.A.Sc. Thesis, University of Toronto, Canada.

24. Quirion, M. and Ballivy, G. (2000). Concrete Strain Monitoring with Fabry-Perot Fiber Optic Sensor, ASCE Journal of Materials in Civil Engineering, 12 (3): 254-261. 


\section{LIST OF TABLES}

Table 1: Summary of the test plan

Table 2: Proportioning of the concrete mixtures

Table 3: Summary of post-corrosion test results

\section{FIGURE CAPTIONS}

Figure 1. The concept of functionally graded concrete.

Figure 2. Beam dimensions and instrumentations (all dimensions in $\mathrm{mm}$ ).

Figure 3. (a) Concrete embeddable fibre optic sensor (b) FOSS between longitudinal bars.

Figure 4. The concept of using FOSS to measure the corrosion induced damage.

Figure 5. Average corrosion current of different RC beams.

Figure 6. Corrosion-induced tensile strain in the concrete as measured by the FOSS.

Figure 7. Increase of FOSS reading with cumulative steel loss due to accelerated corrosion.

Figure 8. Correlation between steel loss and FOSS readings.

Figure 9. Corrosion crack mapping (progress of corrosion damage according to specified time intervals).

Figure 10. (a) Cracking pattern in corroded OPC concrete beam at about peak load; (b) Close-up of highlighted region of (a) after failure; (c) Status of corroded steel reinforcements

Figure 11. (a) Cracking pattern in corroded FGC beam at about peak load; (b) Close-up of highlighted region of (a) after failure; (c) Status of corroded steel reinforcements

Figure 12. Correlations (a) between the FOSS readings and the reductions in load at failure and (b) between the FOSS readings and the reductions in deflection capacity at failure. 
Table 1: Summary of the test plan

\begin{tabular}{|c|c|c|c|c|c|c|}
\hline $\begin{array}{c}\text { Series } \\
\text { No. }\end{array}$ & Series Name & $\begin{array}{c}\text { Specimen } \\
\text { Designation }\end{array}$ & Mix & $\begin{array}{c}\text { Corrosion } \\
\text { Status }\end{array}$ & $\begin{array}{c}\text { Structural } \\
\text { Testing }\end{array}$ & $\begin{array}{c}\text { FOSS } \\
\text { Gauge }\end{array}$ \\
\hline 1 & OPC concrete & B1 & 1 & No & Yes & No \\
& beam & B1C & 1 & Yes & Yes & Yes \\
\hline 2 & FA concrete & B2 & 2 & No & Yes & No \\
& beam & B2C & 2 & Yes & Yes & Yes \\
\hline 3 & SG concrete & B3 & 3 & No & Yes & No \\
& beam & B3C & 3 & Yes & Yes & Yes \\
\hline 4 & SF concrete & B4 & 4 & No & Yes & No \\
& beam & B4C & 4 & Yes & Yes & Yes \\
\hline 5 & FGC beam & B5 & 5 & No & Yes & No \\
& & B5C & 5 & Yes & Yes & Yes \\
\hline
\end{tabular}

Table 2: Proportioning of the concrete mixtures

\begin{tabular}{|c|c|c|c|c|c|c|c|c|c|}
\hline \multirow{2}{*}{ Mix } & \multicolumn{6}{|c|}{ Quantities $\left(\mathrm{Kg} / \mathrm{m}^{3}\right)$} & \multicolumn{2}{|c|}{$\begin{array}{c}\text { Cement } \\
\text { Partial } \\
\text { Replacement }\end{array}$} & \multirow{2}{*}{$\begin{array}{c}\text { 28-day } \\
\text { Cylinder } \\
\text { Compressive } \\
\text { Strength } \\
\text { (MPa) }\end{array}$} \\
\hline & Cement & SCM & F.A. ${ }^{a}$ & C.A. ${ }^{b}$ & Water & $\mathrm{WRA}^{\mathrm{c}}$ & SCM & $\%$ & \\
\hline 1 & 370 & 0 & 753 & 1129 & 163 & 2.2 & - & - & 40.8 \\
\hline 2 & 185 & 185 & 753 & 1129 & 163 & 2.2 & FA & 50 & 46.1 \\
\hline 3 & 185 & 185 & 753 & 1129 & 163 & 2.2 & SG & 50 & 45.9 \\
\hline 4 & 333 & 37 & 753 & 1129 & 163 & 3.7 & SF & 10 & 50.4 \\
\hline $5 A^{d}$ & 370 & 0 & 753 & 1129 & 163 & 2.2 & - & - & 41.6 \\
\hline $5 \mathrm{~B}^{\mathrm{e}}$ & 1250 & 1250 & 2500 & - & 1125 & 4.0 & FA & 50 & 61.3 \\
\hline
\end{tabular}

${ }^{\mathrm{a}} \mathrm{F} . \mathrm{A} .=$ fine aggregate, river sand having fineness modulus of 2.96 ;

${ }^{\mathrm{b}} \mathrm{C} . \mathrm{A} .=$ coarse aggregate, crushed granite with a maximum size of $12.5 \mathrm{~mm}$ and fineness modulus of 6.05 ;

${ }^{\mathrm{c}} \mathrm{WRA}=$ Water reducing admixture;

${ }^{\mathrm{d}}$ Plain concrete used in the top two-third portion of the FGC beam;

${ }^{\mathrm{e}}$ DFRCC material containing $1.5 \%$ PVA and $1 \%$ steel fiber (by volume). 
Table 3: Summary of post-corrosion test results

\begin{tabular}{|c|c|c|c|c|c|c|c|c|c|c|}
\hline \multirow{3}{*}{$\begin{array}{c}\text { Specimen } \\
\text { Designation }\end{array}$} & \multirow{3}{*}{$\begin{array}{l}\text { Yield } \\
\text { Load } \\
(\mathrm{kN})\end{array}$} & \multirow{3}{*}{$\begin{array}{l}\text { Peak } \\
\text { Load } \\
(\mathrm{kN})\end{array}$} & \multicolumn{2}{|c|}{ Load at Failure $^{\mathrm{a}}$} & \multicolumn{2}{|c|}{ Deflection at Failure } & \multirow{2}{*}{\multicolumn{2}{|c|}{$\begin{array}{c}\text { Average } \\
\text { Corrosion } \\
\text { Current (amps) }\end{array}$}} & \multirow{3}{*}{$\begin{array}{l}\text { Steel } \\
\text { Loss } \\
(\%)\end{array}$} & \multirow{3}{*}{$\begin{array}{c}\text { FOSS } \\
\text { Reading } \\
(\mu \varepsilon)\end{array}$} \\
\hline & & & \multirow[b]{2}{*}{$\begin{array}{l}\text { Load } \\
(\mathrm{kN})\end{array}$} & \multirow[b]{2}{*}{$\begin{array}{l}\% \text { of } \\
\text { control }\end{array}$} & \multirow[b]{2}{*}{$\begin{array}{l}\text { Deflection } \\
(\mathrm{mm})\end{array}$} & \multirow[b]{2}{*}{$\left|\begin{array}{c}\% \text { of } \\
\text { control }\end{array}\right|$} & & & & \\
\hline & & & & & & & $\begin{array}{l}\text { Wet } \\
\text { cycle }\end{array}$ & $\begin{array}{l}\text { Dry } \\
\text { cycle }\end{array}$ & & \\
\hline B1 & 211 & 227 & 215.6 & - & 28.5 & - & - & - & - & - \\
\hline $\mathrm{B} 1 \mathrm{C}$ & 184 & 197 & 187.4 & 87 & 24.0 & 84 & 1.20 & 0.07 & 9.7 & 1552 \\
\hline $\mathrm{B} 2$ & 201 & 216 & 205.2 & - & 28.0 & - & 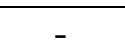 & - & - & 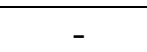 \\
\hline $\mathrm{B} 2 \mathrm{C}$ & 200 & 209 & 198.6 & 97 & 25.0 & 89 & 0.38 & 0.05 & 3.3 & 185 \\
\hline B3 & 214 & 234 & 222.3 & - & 25.3 & - & - & - & - & - \\
\hline $\mathrm{B} 3 \mathrm{C}$ & 206 & 222 & 210.9 & 95 & 20.0 & 79 & 0.65 & 0.03 & 4.6 & 288 \\
\hline B4 & 214 & 222 & 210.9 & - & 19.6 & - & - & - & - & - \\
\hline $\mathrm{B} 4 \mathrm{C}$ & 196 & 202 & 191.9 & 91 & 18.0 & 92 & 1.00 & 0.04 & 7.0 & 897 \\
\hline B5 & 234.6 & 239 & 226.3 & - & 27.2 & - & - & - & - & - \\
\hline B5C & 224.4 & 227 & 215.6 & 95 & 27.2 & 100 & 0.81 & 0.05 & 6.6 & 277 \\
\hline
\end{tabular}

${ }^{\mathrm{a}}$ beams are considered to have failed once the applied load drops to about 95 percent of the peak load 


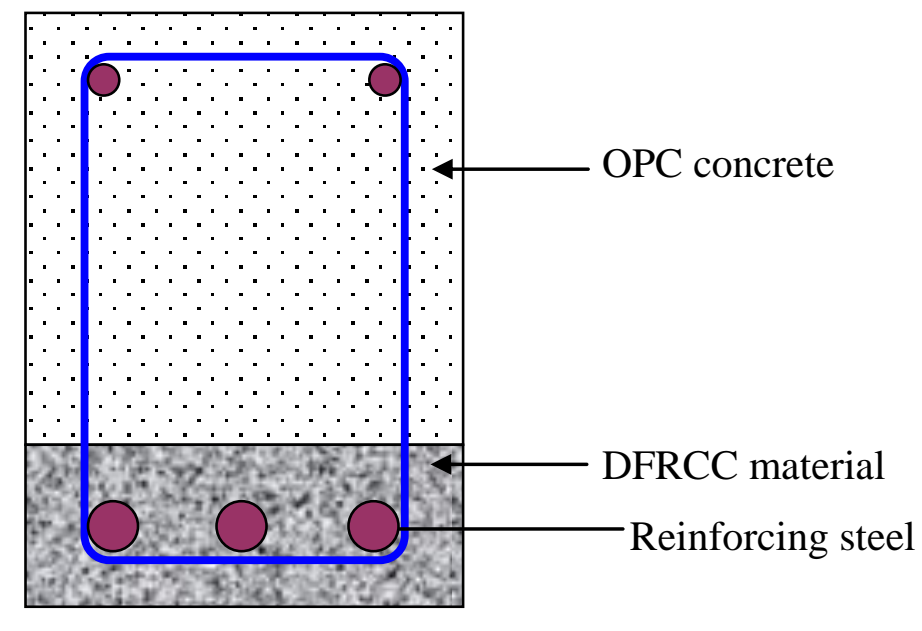

Figure 1 . The concept of functionally graded concrete (FGC)

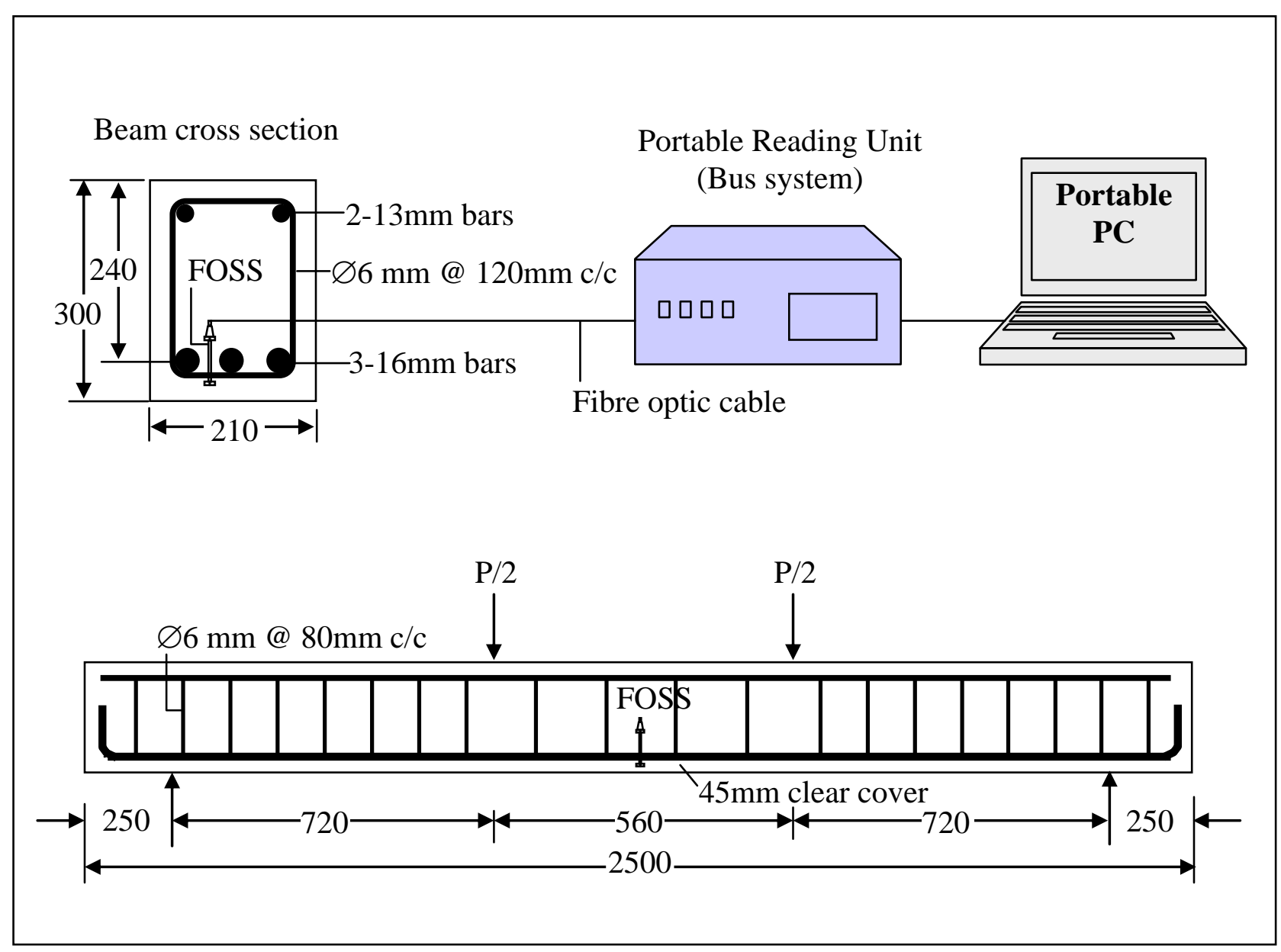

Figure 2. Beam dimensions and instrumentations (all dimensions in $\mathrm{mm}$ ). 


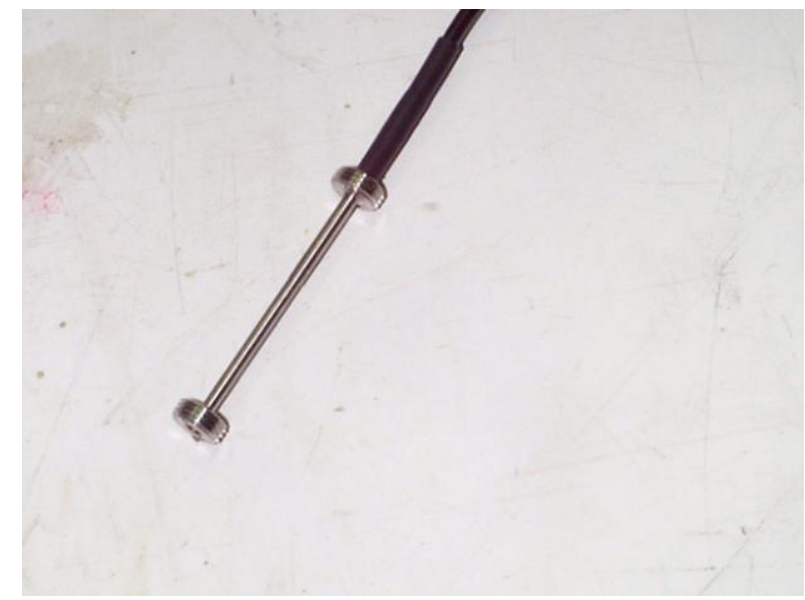

(a)

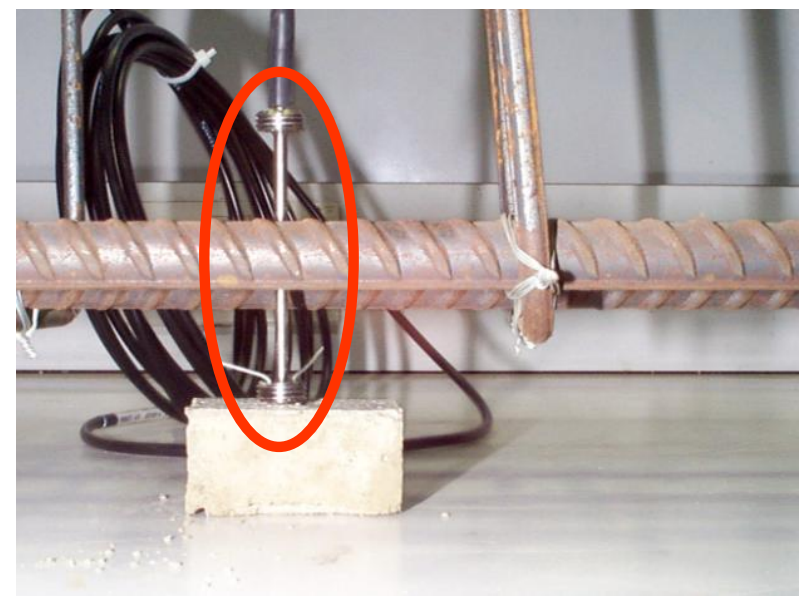

(b)

Figure 3. (a) Concrete embeddable fibre optic sensor (b) FOSS between longitudinal bars. 


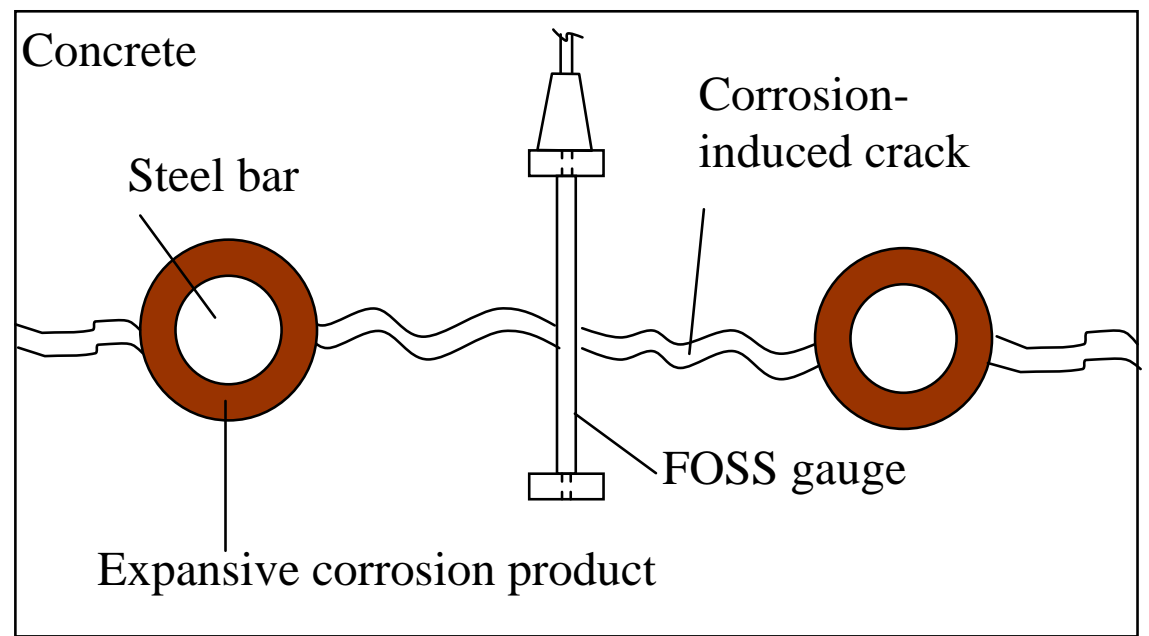

Figure 4. The concept of using FOSS to measure corrosion-induced damage.

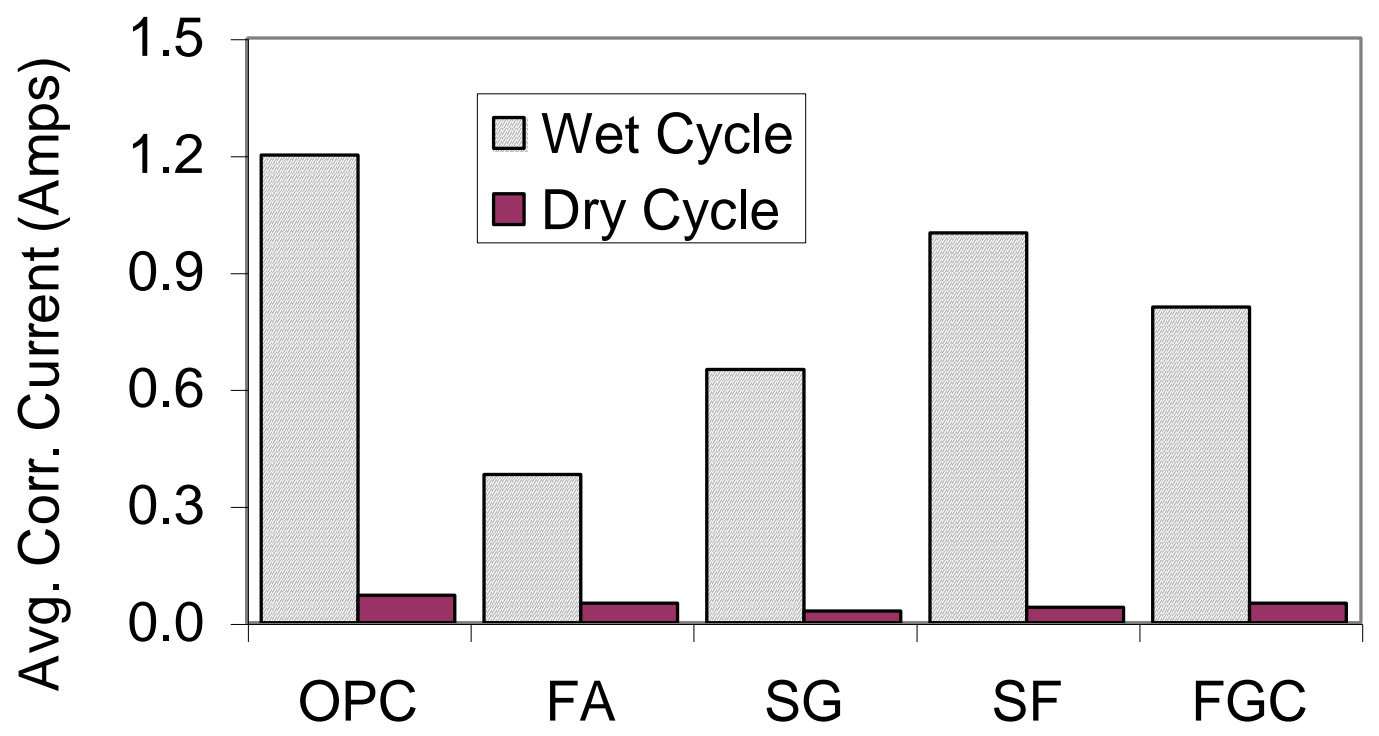

Figure 5. Average corrosion current of different RC 


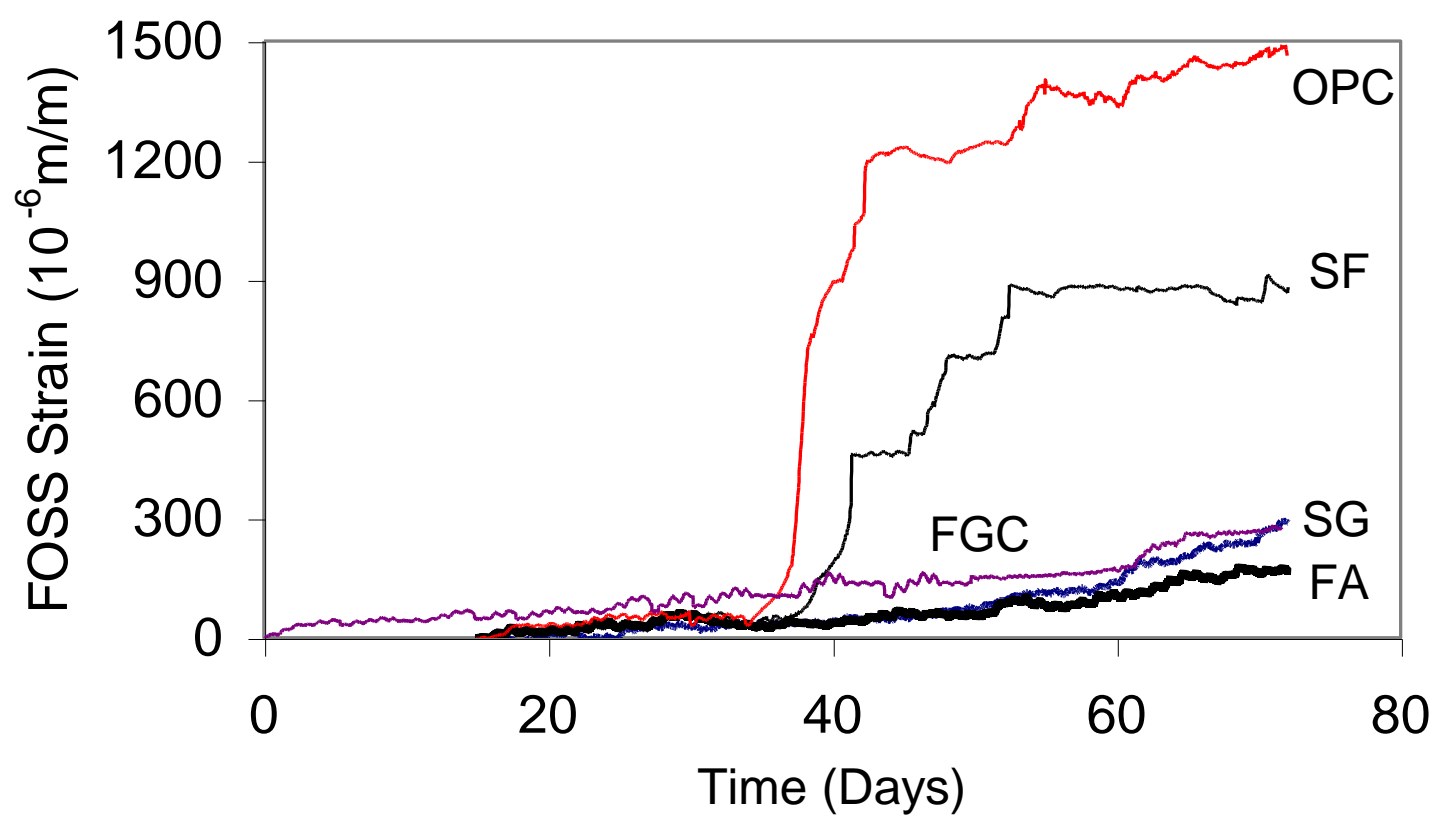

(a)

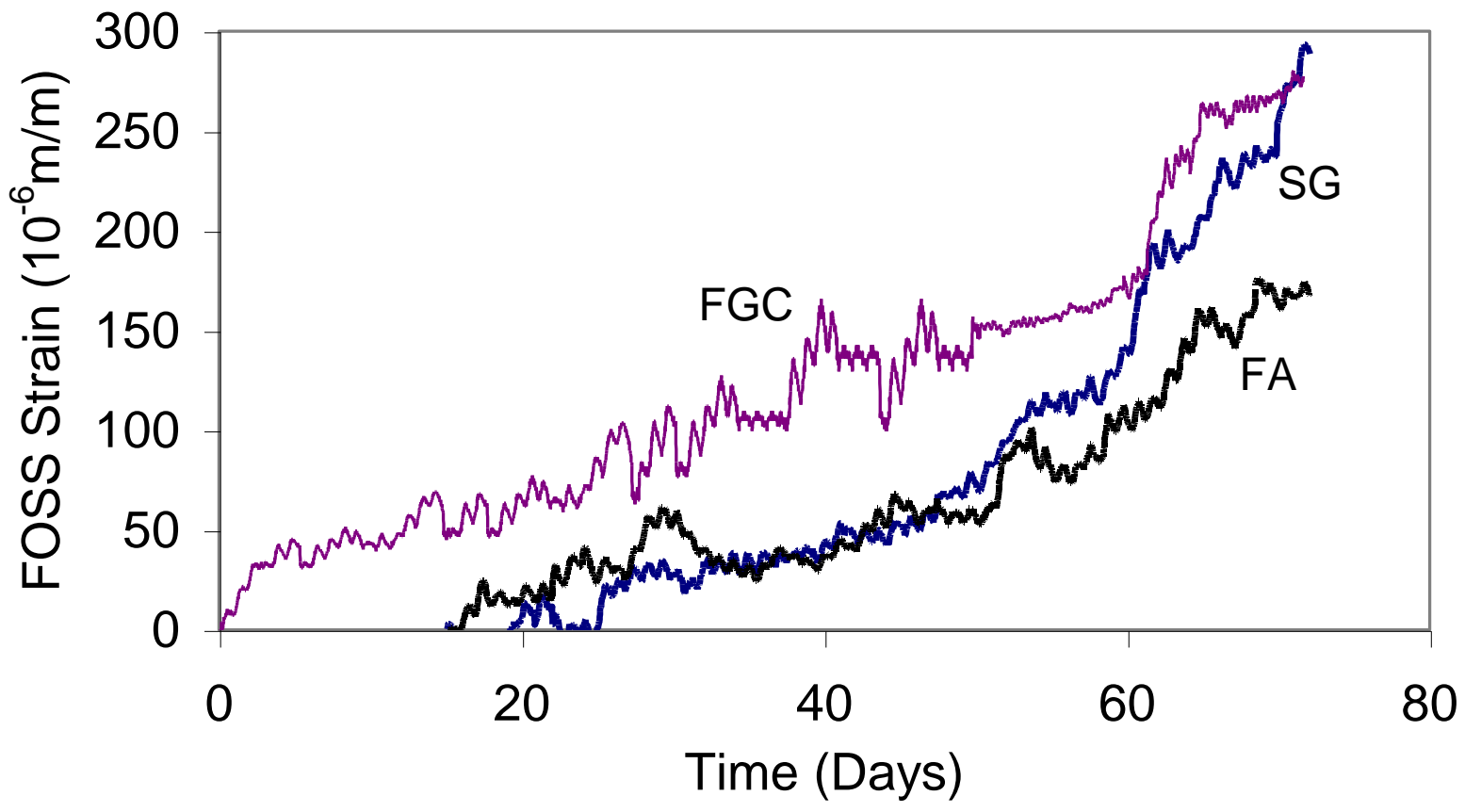

(b)

Figure 6. Corrosion-induced tensile strain in the concrete as measured by the FOSS (a) all beams (b) close-up for selected beams 


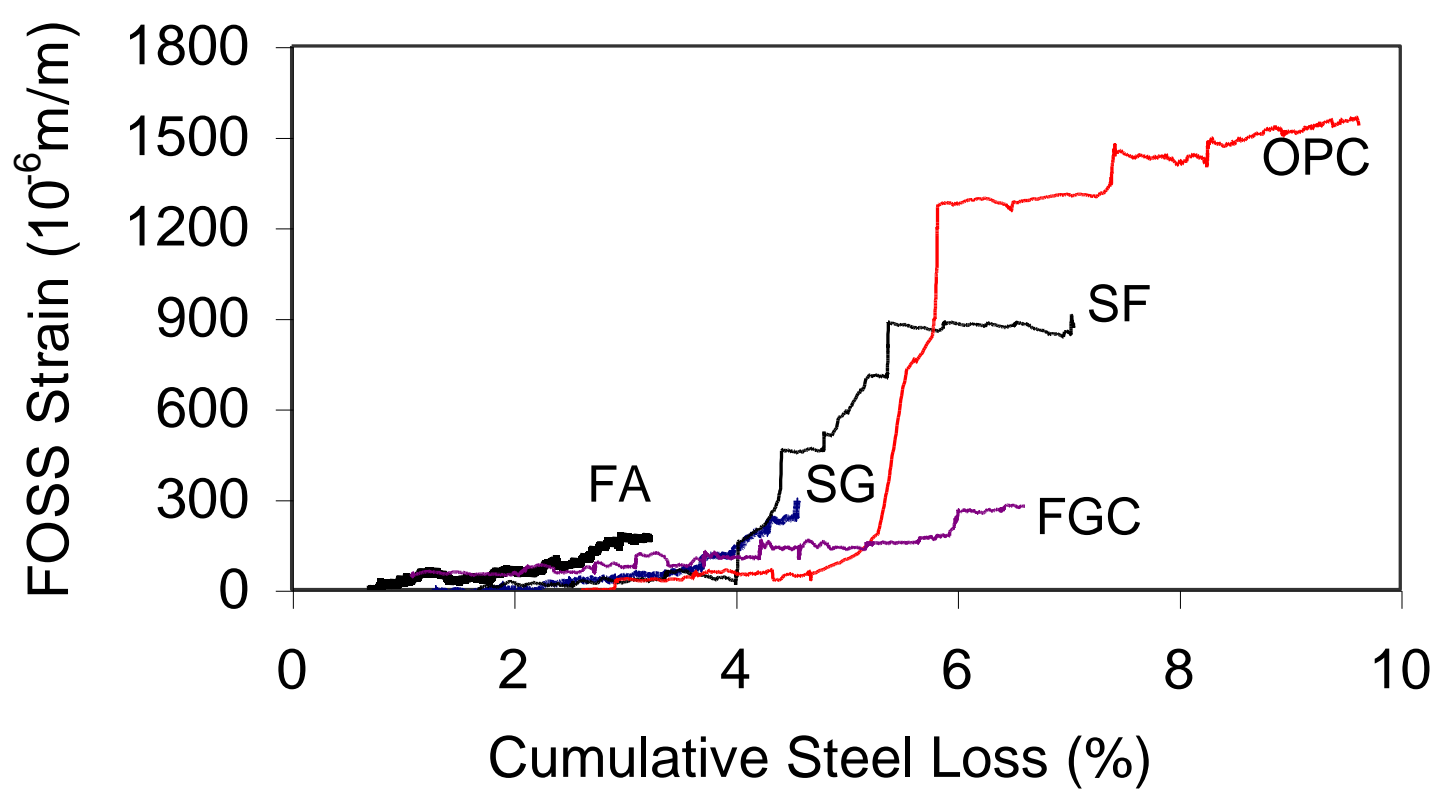

(a)

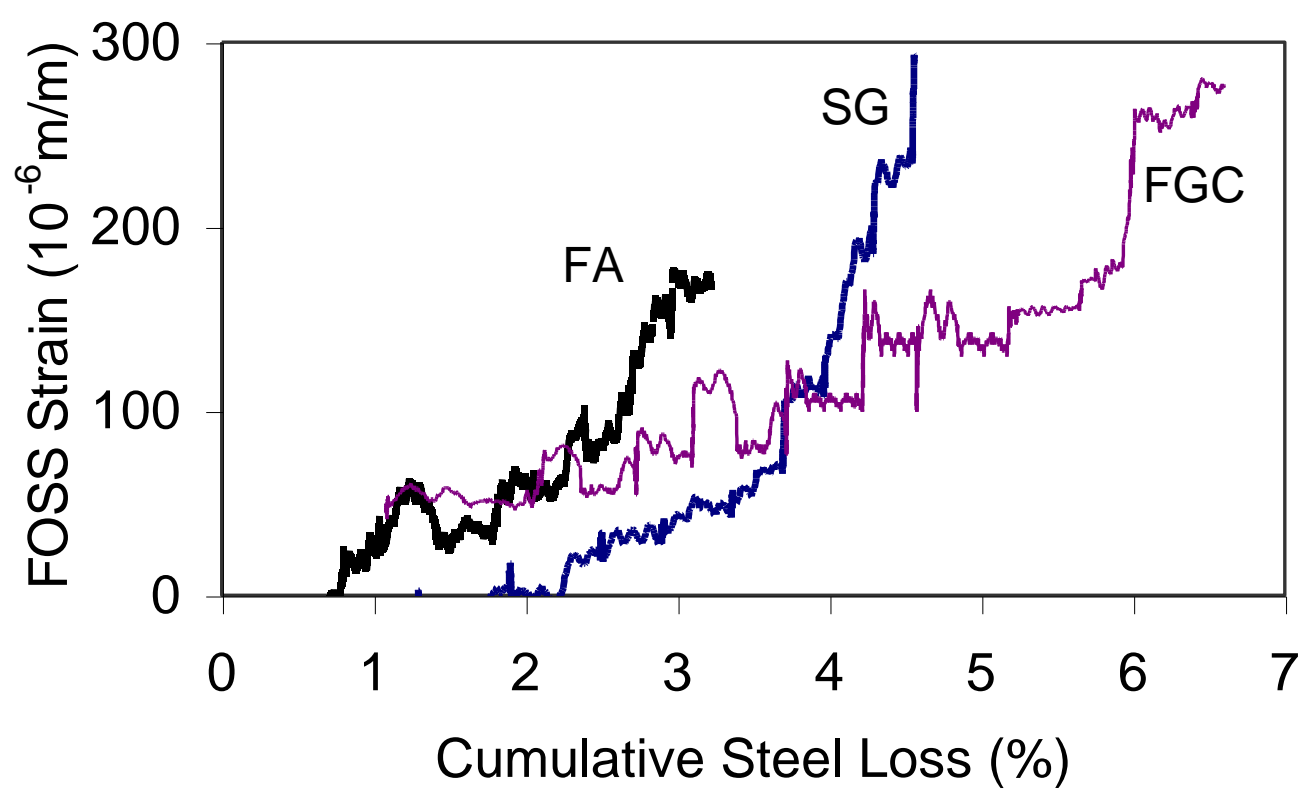

(b)

Figure 7. Increase of FOSS reading with cumulative steel loss due to accelerated corrosion (a) all beams (b) close-up for selected beams 


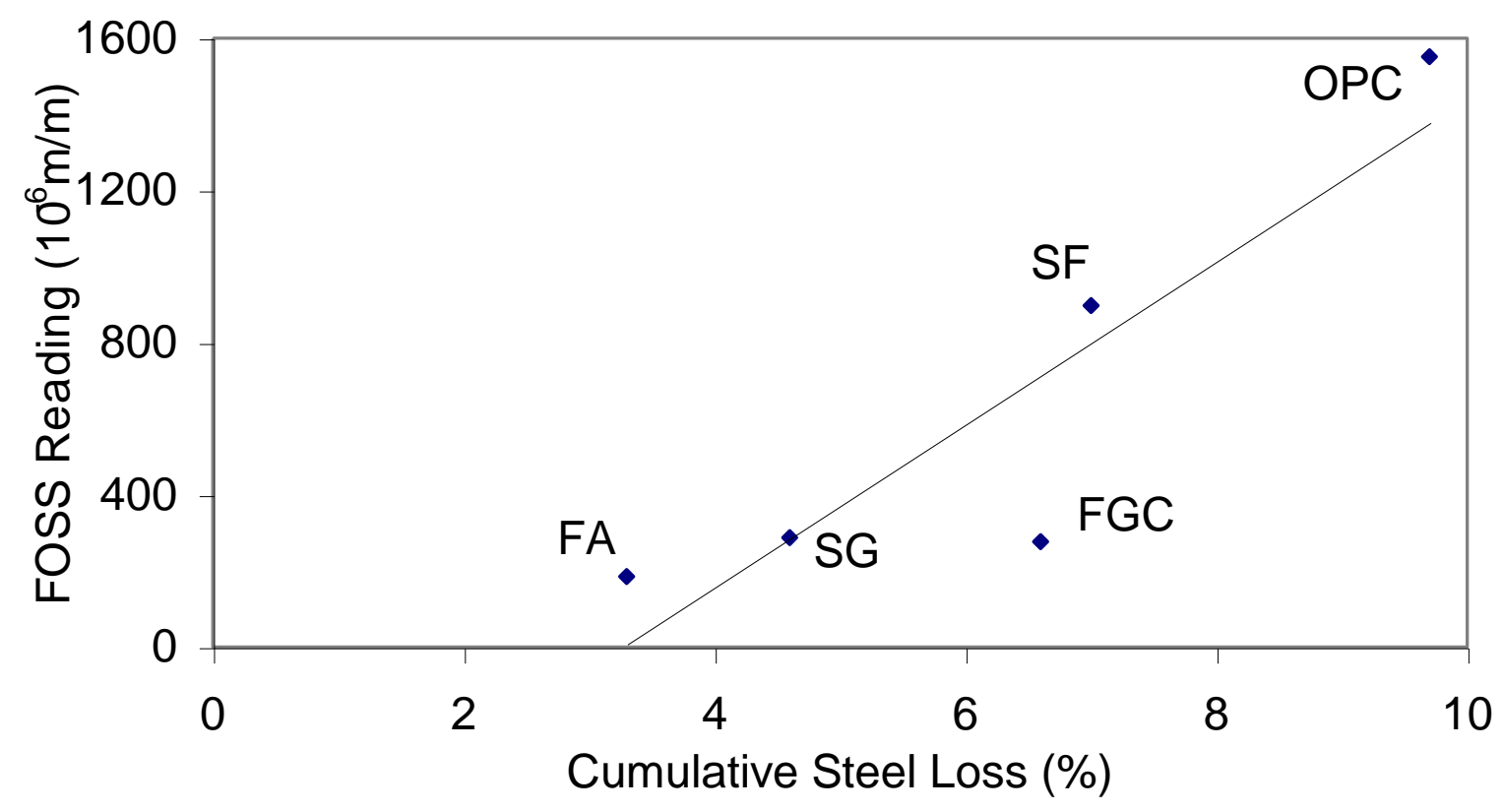

Figure 8. Correlation between steel loss and FOSS readings. 
(a)

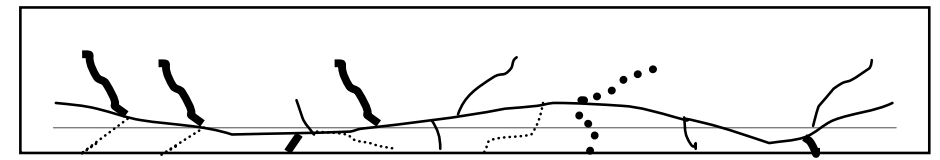

Side

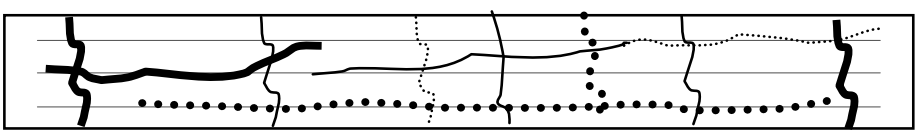

Bottom

(b)

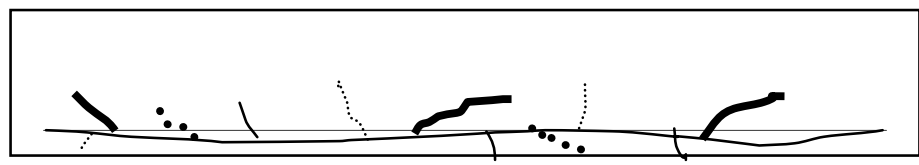

Side

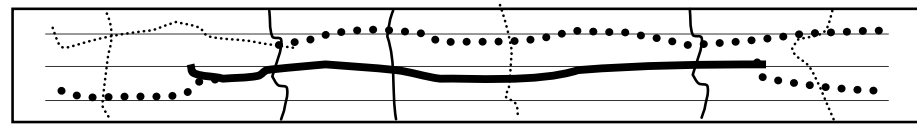

Bottom

(c)

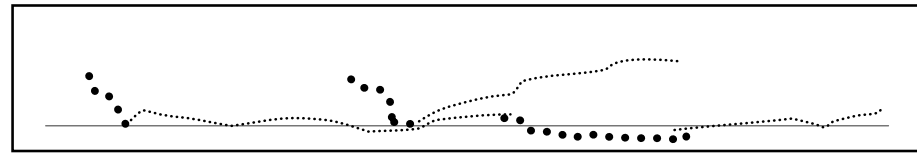

Side

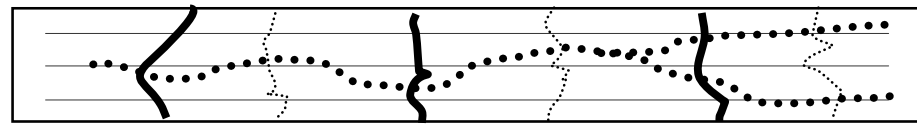

Bottom

(d)

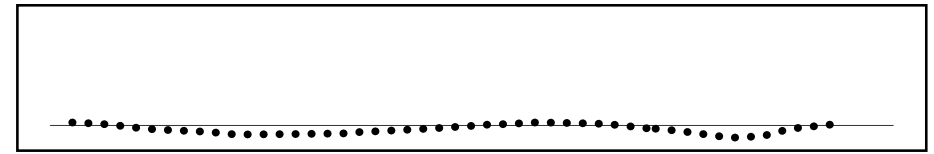

Side

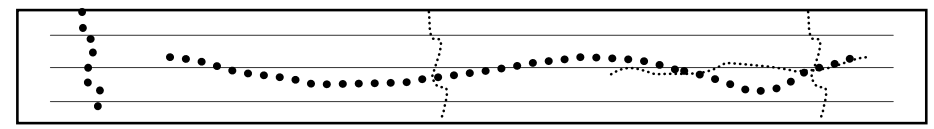

Bottom

(e)

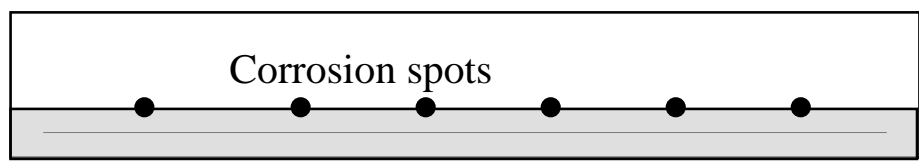

Side

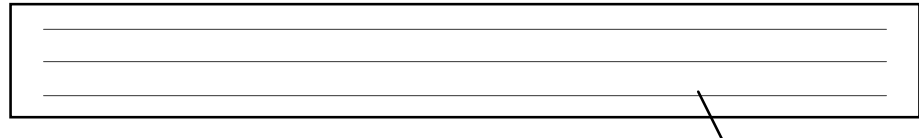

Bottom

30 days

45 days

60 days

74 days (a) OPC concrete beam;

(b) SF concrete beam;

(c) SG concrete beam;

(d) FA concrete beam;

(e) FGC beam.

Figure 9. Corrosion crack mapping (progress of corrosion damage according to specified time intervals). 


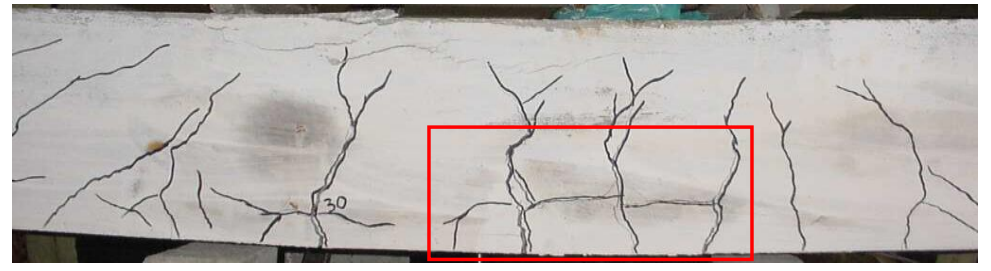

(a)

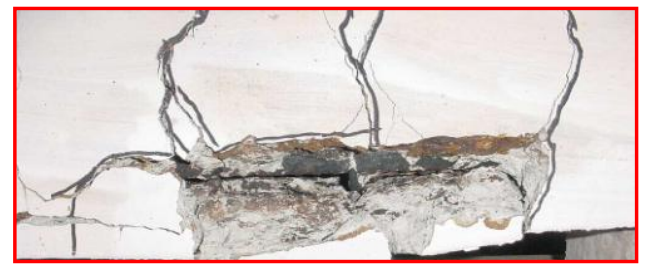

(b)

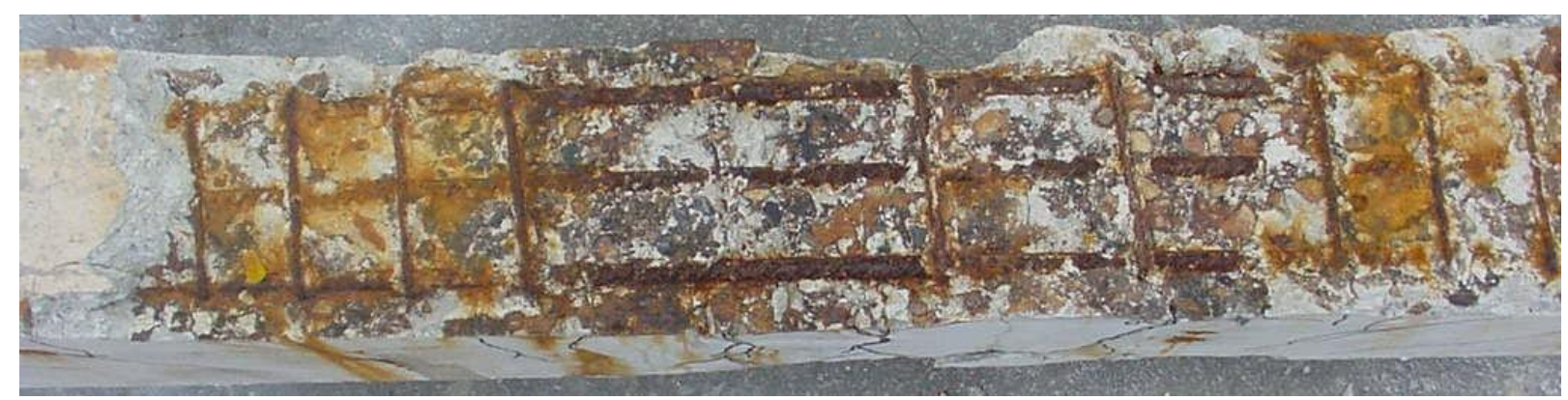

(c)

Figure 10. (a) Cracking pattern in corroded OPC concrete beam at about peak load; (b) Close-up of highlighted region of (a) after failure; (c) Status of corroded steel reinforcements 


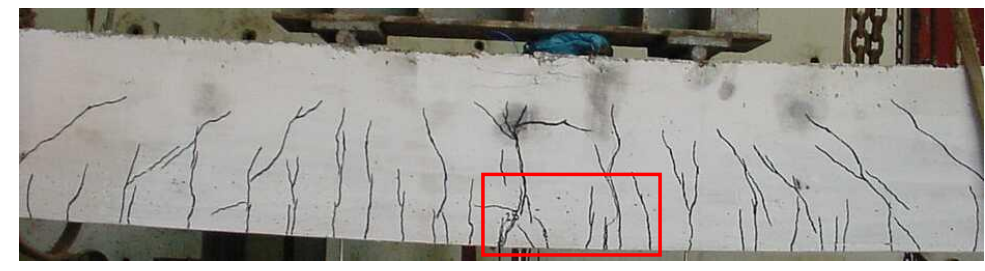

(a)

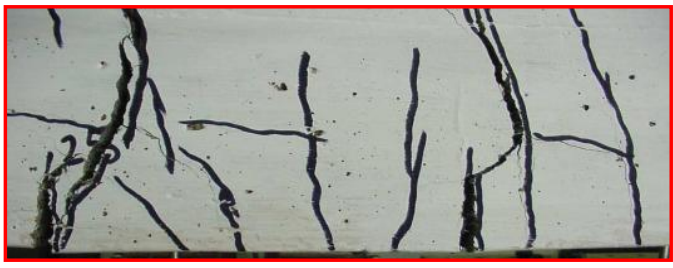

(b)

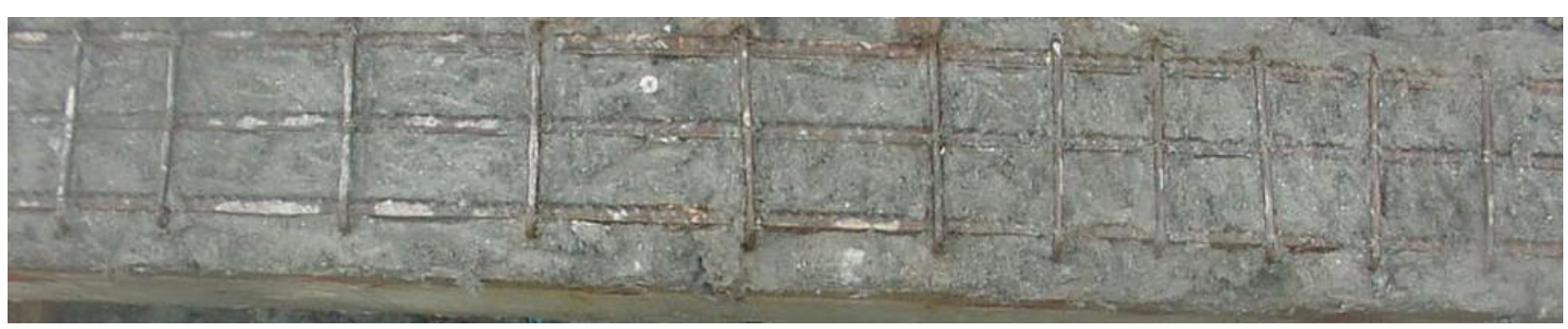

(c)

Figure 11. (a) Cracking pattern in corroded FGC beam at about peak load; (b) Close-up of highlighted region of (a) after failure; (c) Status of corroded steel reinforcements 


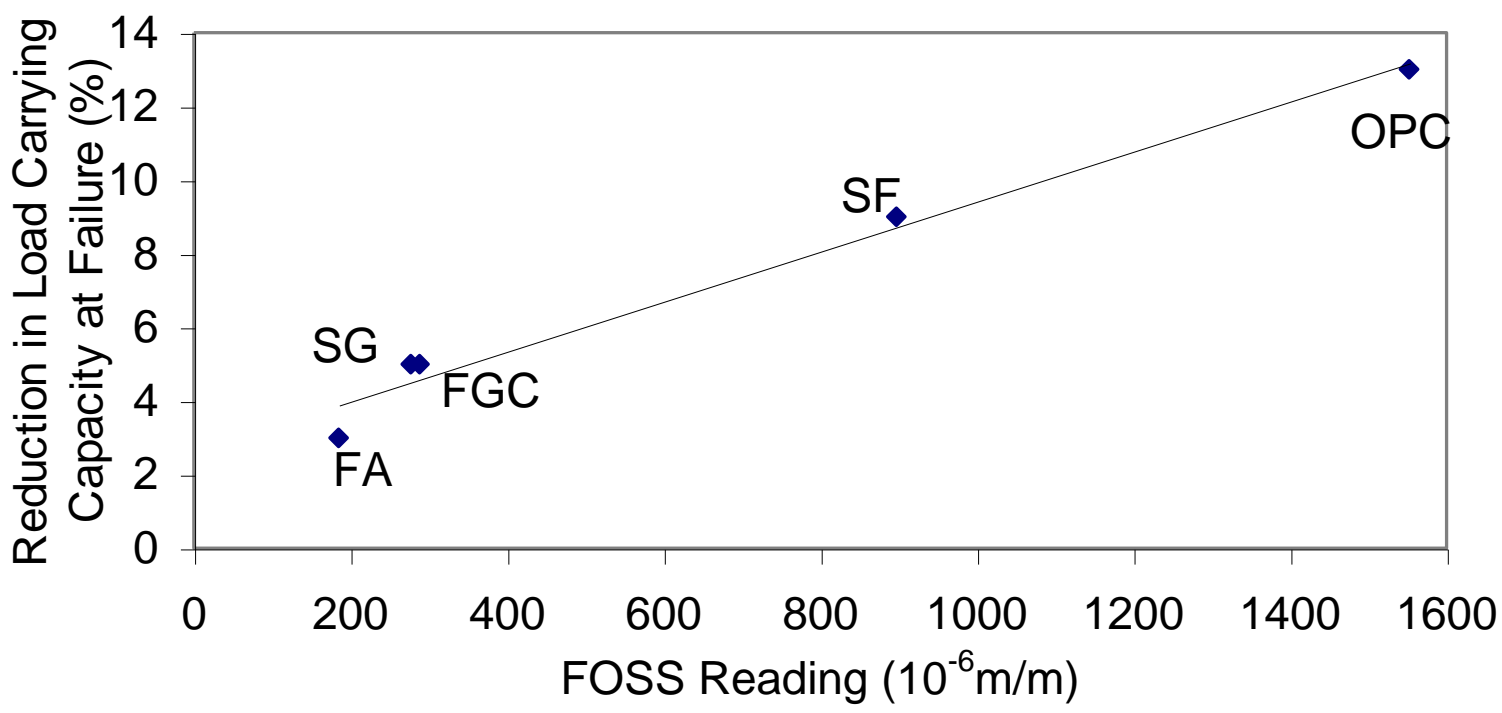

(a)

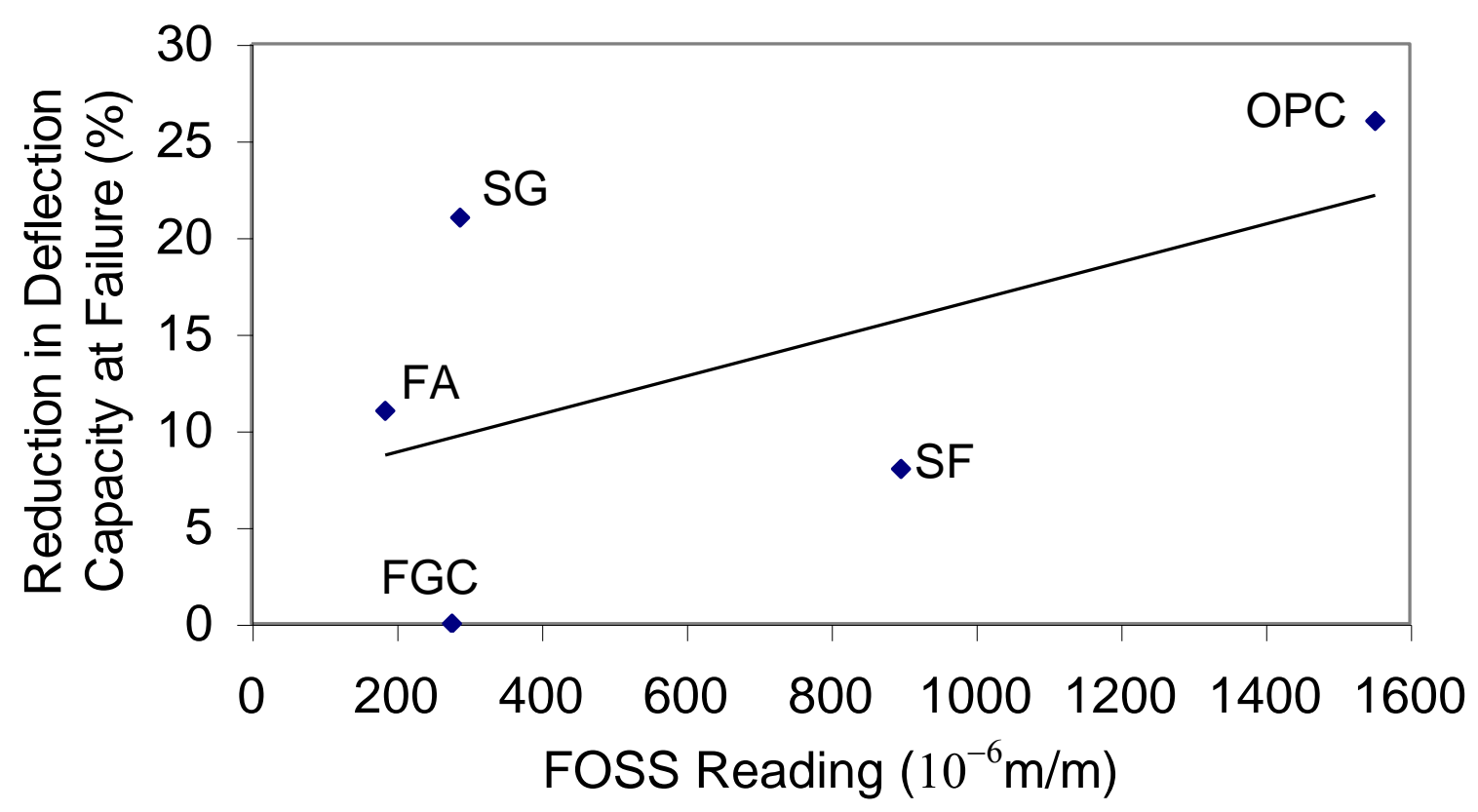

(b)

Figure 12. Correlations (a) between the FOSS readings and the reductions in load at failure and (b) between the FOSS readings and the reductions in deflection capacity at failure. 